\title{
Measuring Quality of Life Following Robot-Assisted Radical Prostatectomy
}

\author{
Graham R Hale' \\ Mohammed Shahait $\left.{ }^{2}\right)^{2}$ \\ David I Lee ${ }^{3}$ \\ Daniel J Lee ${ }^{4}$ \\ Ryan W Dobbs $\mathbb{D}^{5}$ \\ 'Department of Urology, University of \\ Illinois at Chicago, Chicago, IL, USA; \\ ${ }^{2}$ Department of Urology, King Hussein \\ Cancer Foundation and Center, Amman, \\ Jordan; ${ }^{3}$ Department of Urology, \\ University of California at Irvine, Irvine, \\ CA, USA; ${ }^{4}$ Division of Urology, \\ University of Pennsylvania, Philadelphia, \\ PA, USA; ${ }^{5}$ Division of Urology, Cook \\ County Health and Hospitals System, \\ Chicago, IL, USA
}

Background: Prostate cancer (PCa) represents the most common solid organ malignancy in men. Fortunately, at the time of diagnosis, the majority of cases are staged as localized or regional disease, conferring excellent 5- and 10-year cure rates. There are several first line treatment options including surgical approaches such as robot-assisted radical prostatectomy (RARP) and radiation therapy (RT) available to patients with localized disease that offer similar PCa oncologic outcomes but are associated with potentially significant side effects which may impact health-related quality of life (HRQOL) domains. Recently, clinicians and investigators have sought to better understand these changes in HRQOL metrics with the utilization of patient-reported outcomes (PRO). Given that RARP represents the most common surgical treatment for $\mathrm{PCa}$ in the United States, there has been a particular interest in assessing these outcomes derived by patient perspectives to more fully appreciate treatment-related impact on quality of life following RARP.

Objective: This narrative review sought to explore the instruments available to measure quality of life after RARP, a review of the PRO data after RARP, and future directions for assessing and improving quality of life outcomes following this surgery.

Clinical Use: There are several treatment options for men diagnosed with local and regional prostate cancer with similar oncologic outcomes but differing patterns of side effects affecting posttreatment quality of life. Understanding data reported directly by patients following RARP about their side effects and quality of life gives providers additional information for appropriate preoperative counseling for patients choosing between treatment options for their prostate cancer.

Keywords: prostatic neoplasms, minimally invasive surgical procedures, prostatectomy, patient-reported outcomes measures, robotic surgery

\section{Introduction}

Prostate cancer (PCa) represents the most common solid organ malignancy in men, with an estimated 191,930 new cases and 33,330 deaths in $2020 .^{1}$ At the time of diagnosis, $76 \%$ and $13 \%$ of patients will be diagnosed with localized and regional disease, respectively - both with a 100\% 5-year relative survival indicating excellent cure rates. ${ }^{1}$ There are several first line treatment options available to patients with localized disease which offer similar PCa specific survival rates. ${ }^{2-4}$ Additionally, there have been significant changes in treatment paradigms in the last two decades with the advent of active surveillance, modifying radiation dosing schedules, and transition from open radical retropubic prostatectomy (RRP) to robotic assisted laparoscopic radical prostatectomy (RARP) in the United States. $^{2-8}$ By 2013, over $85 \%$ of all prostatectomies performed in the United States were performed utilizing robotic technology. ${ }^{9}$ Despite achieving excellent
Correspondence: Ryan W Dobbs Division of Urology, Cook County Health and Hospitals System, 1950 W Polk Street, Chicago, IL, 606I2

Email Ryan.Dobbs@cookcountyhhs.org 
oncologic outcomes, PCa treatment may result in significant side effects such as urinary incontinence (UI) and erectile dysfunction (ED) that may negatively affect multiple health-related quality-of-life (HRQOL) domains. Understanding and measuring these side effects gives patients and providers additional data with which to compare the available treatment options. In this review, we sought to evaluate the background and rationale for using quality of life metrics and patient-reported outcomes (PRO), the current available literature regarding the use of these instruments by urologists following RARP as well as future directions for assessing and improving quality-of -life outcomes following this surgery.

\section{Methods}

A comprehensive literature search and review was performed using the PubMed, Scopus and Google Scholar databases from the time period 1990 to 2021 with a particular emphasis following the introduction of the da Vinci surgical platform (Intuitive Surgical Inc., Sunnyvale, CA, USA) in 2000. Search terms included: prostate cancer, robotic assisted laparoscopic radical prostatectomy, radical retropubic prostatectomy, patient-reported outcomes, patient-reported outcome measures, and health-related quality of life. Primary weighting was applied to general reviews, meta-analyses, randomized controlled trials, and validated and heavily used patientreported outcome measures. Secondary attention was given to retrospective studies and descriptive studies.

\section{Findings}

\section{Assessing Quality of Life \& Patient- Reported Outcomes}

In 1946, the World Health Organization's (WHO) constitution redefined health as a "state of complete physical, mental, and social well-being" and not "merely the absence of disease."10 This definition helped break the concept of health into component parts, or domains, that required new methods to measure and report patient reported data despite the associated challenges. This helped propel the development of psychometric testing, or creating instruments designed to provide objective measurements of difficult to quantify phenomena, like Patient-Reported Outcomes (PRO). PRO are those that come directly from patients' without interpretation by anyone else, and patient-reported outcome measures (PROM) are the instruments used to measure and report them. ${ }^{11}$ A validated PROM is one that undergoes rigorous testing and is proven to display three psychometric properties within its testing population: reliability, will produce a similar result every time; validity, measures what it is intended to measure; and responsiveness, ability of the instrument to detect changes over time when they occur. ${ }^{12}$ Validated PROM have been proven to be effective tools in quantifying subjective symptoms and have received increased attention recently in part from the emphasis on patient centered care from the Affordable Care Act. ${ }^{13,14}$

\section{Current Quality of Life Instruments}

There are an incredible number of PROM within the medical literature, each covering domains specific to their aims and with varying degrees of quality leading to challenges with cross-study comparisons. Several large-scale efforts have been launched to address this problem. The National Institutes of Health (NIH) Patient-Reported Outcomes Measurement Information System (PROMIS) was created in 2004 and tasked to "develop, validate, and standardize" tools used to measure and report PRO. ${ }^{15,16}$ Currently, there are 587 English language PROMIS instruments available for research use, some of which may measure domains relevant to urologists. $^{17}$ In 2011, the National Cancer Institute's (NCI) Symptom Management and Health-Related Quality of Life Steering Committee arranged a Clinical Trials Planning Meeting that provided a recommended core set of patient reported symptoms to include in oncology trials, with an expert panel that focused on PCa as one of the three specific diseases addressed during this meeting. ${ }^{18,19}$ While not endorsing specific PROM, the panel did provide a list of recommended PRO and five HRQOL domains to be measured in localized cancer clinical trials: urinary incontinence, urinary obstruction and irritation, bowel-related symptoms, sexual dysfunction, and hormonal symptoms. ${ }^{18,19}$ Founded in 2010 as part of the Affordable Care Act, the Patient-Centered Outcomes Research Institute funds research that provides evidence-based information to patients and providers they can "use to make decisions that reflect their desired health outcomes" and has generated several contemporary studies reporting on urologic diseases, their treatments, and side effects. $^{20,21}$

\section{Utilization of Quality-of-Life Metrics in Urology}

Urologists have developed and validated different disease specific PROM in an effort to provide more targeted assessments and information for patients and providers. ${ }^{22}$ 
Prior to the robotic surgery era, there were many efforts to use PROM to measure HRQOL and effects from treating localized PCa and even compare PRO from the various treatment modalities. ${ }^{23-28}$ As the development of PROM continued to produce better instruments, there were some efforts to retrospectively apply these, although this proved inaccurate as patients tended to remember their preintervention health to be better than it was. ${ }^{29}$ Despite the longevity of these efforts, there is still not a consensus on the PROM, or collection of PROMs, used to study localized PCa. However, the NCI's Clinical Trials Planning Meeting recommended all localized PCa clinical trials assess a core set of PRO and HLQOL domains: urinary incontinence, urinary obstruction and irradiation, bowelrelated symptoms, sexual dysfunction, and hormonal symptoms. ${ }^{18}$ As such, several high-quality PROM are commonly used in the study of localized PCa, both clinically and in research. Table 1 provides an overview of the commonly used PROM in localized PCa, the domains captured, the population demographics in which they were validated, and their basic arrangement, when this information is available (Table 1). ${ }^{30-37}$ Furthermore, some of the more ubiquitous instruments have undergone additional validation for "bi-directional crosswalks", allowing for domain scores from one instrument to be converted into those of another, facilitating easier cross study comparison between certain instruments. ${ }^{38}$ This information may aid in selecting the most appropriate instrument for studies and ensure that they are being used, and thus interpreted, as designed.

\section{Quality of Life Following Robotic Radical Prostatectomy}

Since the first RARP was performed in 2001, the treatment paradigm for PCa from traditional open surgery rapidly shifted towards RARP as the preferred surgical approach, by 2013, over $85 \%$ of all prostatectomies were being performed with robotic technology. ${ }^{5-9}$ The rapid adoption of RARP was driven

Table I Validated QOL Questionnaires

\begin{tabular}{|c|c|c|c|c|c|}
\hline Name & Purpose & $\begin{array}{c}\text { Year } \\
\text { Published }\end{array}$ & Domains & Measurement & $\begin{array}{c}\# \\
\text { Items }\end{array}$ \\
\hline $\begin{array}{l}\text { PROMIS- } \\
\text { SexFS } v 2^{31}\end{array}$ & $\begin{array}{l}\text { Male and Female cancer patient } \\
\text { sexual function and satisfaction. }\end{array}$ & 2015 & $\begin{array}{l}\text { Interest, Satisfaction, Orgasm, Erectile } \\
\text { Function }\end{array}$ & $\begin{array}{l}5 \text { Point Likert Scale, } 30- \\
\text { day period }\end{array}$ & $|3|$ \\
\hline $\mathrm{IIEF}^{32}$ & $\begin{array}{l}\text { To detect treatment-related } \\
\text { changes in males with ED }\end{array}$ & 1997 & $\begin{array}{l}\text { Erectile Function, Orgasm Function, } \\
\text { Interest, Intercourse Satisfaction, } \\
\text { Overall Satisfaction }\end{array}$ & $\begin{array}{l}5 \text { Point Likert Scale, } 30- \\
\text { day period }\end{array}$ & 15 \\
\hline $\mathrm{SHIM}^{30}$ & $\begin{array}{l}\text { Screening and } \mathrm{dx} E D \text { and severity, } \\
\text { derivative of IIEF }\end{array}$ & 2000 & $\begin{array}{l}\text { Erectile Function, Orgasm Function, } \\
\text { Sexual Satisfaction }\end{array}$ & $\begin{array}{l}5 \text { Point Likert Scale, } \\
\text { 6-month period }\end{array}$ & 5 \\
\hline $\mathrm{EPIC}^{34}$ & $\begin{array}{c}\text { PCa HRQOL in contemporary } \\
\text { treatment modalities, expansion } \\
\text { of UCLA-PCI }\end{array}$ & 2000 & $\begin{array}{l}\text { Urinary, Bowel, Sexual and Hormonal } \\
\text { Symptoms and Function }\end{array}$ & $\begin{array}{l}5 \text { Point Likert Scale, } \\
\text { 4-week period }\end{array}$ & 25 \\
\hline $\begin{array}{l}\text { EORTC, } \\
\text { Prostate }\end{array}$ & $\begin{array}{c}\text { Multidimensional self- } \\
\text { administered } \mathrm{QOL} \text { instrument for } \\
\mathrm{PCa}\end{array}$ & 1996 & $\begin{array}{l}\text { Urinary, Bowel, and Hormonal } \\
\text { treatment-related sx, sexual function }\end{array}$ & 4 Point Likert Scale & 25 \\
\hline FACT-P $\mathrm{P}^{33}$ & Measure $\mathrm{QOL}$ in patient $\mathrm{PCa}$ & 1997 & $\begin{array}{c}\text { Well being, weight, appetite, voiding } \\
\text { bother, bowel fx, erections, pain, } \\
\text { overall satisfaction }\end{array}$ & $\begin{array}{l}5 \text { Point Likert Scale, past } \\
7 \text { days }\end{array}$ & 39 \\
\hline SF- $-36^{36}$ & $\begin{array}{l}\text { Health Status and Function across } \\
\qquad 8 \text { concepts }\end{array}$ & 1992 & $\begin{array}{l}\text { Limitations of activities, social, usual } \\
\text { roles. Pain, mental health, vitality, } \\
\text { general health }\end{array}$ & $\begin{array}{c}\text { Multi item scale: yes/no, } 3 \\
\text { and } 5 \text { Point Likert Scale, } \\
\text { last year }\end{array}$ & 36 \\
\hline $\begin{array}{l}\text { UCLA } \\
\text { Prostate } \\
\text { Cancer } \\
\text { Index }\end{array}$ & $\begin{array}{l}\text { HRQOL from early stage PCa } \\
\text { specific symptoms across } \\
\text { treatment modalities }\end{array}$ & 1998 & $\begin{array}{l}\text { Urinary Function/bother, Sex function/ } \\
\text { bother, Bowel function/bother }\end{array}$ & $\begin{array}{l}\text { Multi item scale: } 3 \text { to } 6 \\
\text { Point Likert, last } 4 \text { weeks }\end{array}$ & 15 \\
\hline
\end{tabular}


Table 2 RRP vs RARP PROM Comparison Studies Summary

\begin{tabular}{|c|c|c|c|c|c|c|}
\hline Study & Study Design & $\begin{array}{l}\text { Outcome } \\
\text { Measures }\end{array}$ & $\begin{array}{l}\text { Urinary } \\
\text { Domain }\end{array}$ & $\begin{array}{l}\text { Sexual } \\
\text { Domain }\end{array}$ & $\begin{array}{l}\text { Bowel } \\
\text { Domain }\end{array}$ & Other \\
\hline $\begin{array}{l}\text { Coughlin } \\
\text { et } \mathrm{al}^{46}\end{array}$ & $\begin{array}{l}\text { Randomized prospective trial } \\
\text { measuring PRO at } 6,12 \text { and } 24 \\
\text { months between RRP \& RARP }\end{array}$ & $\begin{array}{l}\text { EPIC, IIEF, } \\
\text { HADS }\end{array}$ & $\begin{array}{l}\text { No difference } \\
\text { in EPIC } \\
\text { urinary } \\
\text { domain scores } \\
\text { at } 6,12 \text { and } \\
24 \text { months }\end{array}$ & $\begin{array}{l}\text { No difference } \\
\text { in EPIC sexual } \\
\text { domain } \\
\text { scores at } 6 \text {, } \\
12 \text { and } 24 \\
\text { months }\end{array}$ & $\begin{array}{l}\text { No difference } \\
\text { in EPIC bowel } \\
\text { domain } \\
\text { scores at } 6 \text {, } \\
12 \text { and } 24 \\
\text { months }\end{array}$ & $\begin{array}{l}\text { No differences in physical } \\
\text { and mental QOL, cancer } \\
\text { specific distress, } \\
\text { psychological distress or } \\
\text { vitality at } 6,12 \text { and } 24 \\
\text { months }\end{array}$ \\
\hline $\begin{array}{l}\text { Alemozaffar } \\
\text { et } \mathrm{al}^{43}\end{array}$ & $\begin{array}{l}\text { Prospectively collected data } \\
\text { with biennial questionnaires. } \\
\text { Compare RRP and RARP } \\
\text { between low, intermediate and } \\
\text { high-risk patients. HRQOL } \\
\text { collected as a secondary } \\
\text { endpoint. }\end{array}$ & EPIC 26 & $\begin{array}{l}\text { No difference } \\
\text { in urinary } \\
\text { incontinence } \\
\text { or obstruction } \\
\text { in any group }\end{array}$ & $\begin{array}{l}\text { No difference } \\
\text { in sexual } \\
\text { function in } \\
\text { any group }\end{array}$ & $\begin{array}{l}\text { No difference } \\
\text { in bowel } \\
\text { function in } \\
\text { any group }\end{array}$ & $\begin{array}{l}\text { No difference in hormonal/ } \\
\text { vitality or outcome } \\
\text { satisfaction in any group }\end{array}$ \\
\hline $\begin{array}{l}\text { O'Neil } \\
\text { et } \mathrm{al}^{45}\end{array}$ & $\begin{array}{l}\text { Prospectively collected data } \\
\text { with biennial questionnaires. } \\
\text { Compare RRP and RARP } \\
\text { between low, intermediate and } \\
\text { high-risk patients. HRQOL } \\
\text { collected as a secondary } \\
\text { endpoint. }\end{array}$ & $\begin{array}{l}\text { PCOS used } \\
\text { UCLA PCI, } \\
\text { CEASAR } \\
\text { used EPIC }\end{array}$ & $\begin{array}{l}\text { RARP } \\
\text { function } \\
\text { better than } \\
\text { RRP at } 6 \\
\text { months, same } \\
\text { at } 12 \text { months }\end{array}$ & $\begin{array}{l}\text { RARP } \\
\text { function } \\
\text { better than } \\
\text { RRP at } 6 \text { and } \\
12 \text { months }\end{array}$ & Not assessed & \\
\hline
\end{tabular}

by a multitude of perceived and reported benefits. ${ }^{39}$ The reported benefits of RARP compared to RRP include lower estimated blood loss, lower transfusion rates, lower intraoperative adverse events, less postoperative pain, and shorter hospital stay than RRP. ${ }^{40-43}$ Furthermore, RARP offers anecdotal benefits to the surgeon including a more ergonomic seated position for the surgeon, reduced surgeon fatigue, threedimensional visualization, improved degrees of freedom of the endoscopic instruments, and improved nerve sparing. ${ }^{44}$

The follow-up duration, assessment intervals, specific instruments, and postoperative outcome definitions are not standardized when comparing the functional PRO between RRP and RARP. Furthermore, despite the existence of validated PROM many PRO are still collected during open interviews or with non-validated questionnaires, severely hampering inter-study comparisons. However, recent studies have tried to overcome this problem in using validated PROM to directly compare functional outcomes between RRP and RARP. ${ }^{43,45,46}$ Coughlin et al performed a prospective study that randomized 396 men with clinically localized PCa to RRP or RARP: primary outcomes consisted of the urinary domain of Expanded Prostate Cancer Index Composite (EPIC) instrument and the sexual domain of EPIC and International Index of Erectile Function Questionnaire
(IIEF) instruments, and secondary outcomes consisted of the EPIC bowel domain, physical and mental functioning and fatigue of Short Form-36 (SF-36), cancer specific distress using Revised Impact and Events (RIES), and psychological distress using Hospital Anxiety and Depression Scale (HADS). ${ }^{46}$ O’Neil et al compared PROM data from two prospective cohort studies (Prostate Cancer Outcomes Study [PCOS] and Comparative Effectiveness Analysis of Surgery and Radiation [CEASAR]), 2438 men meeting study criteria, using the EPIC and UCLA Prostate Cancer Index (PCI) instruments. ${ }^{45}$ Lastly, Alemozaffar et al reported HRQOL outcomes in 600 men using the EPIC-26 questionnaire. ${ }^{43}$ Basic study design and outcomes are shown in Table 2.

\section{Urinary Symptoms}

Early studies suffer from using different definitions of urinary incontinence, not routine use of PROM, and poor follow-up, complicating direct comparisons. ${ }^{47}$ Urinary domain results are summarized in Table 3. A meta-analysis by De Carlo et al defined continence as "the use of no absorbent pads or no leakage at all", reporting continence rates between RRP and RARP, with RARP achieving superior continence rates at 6 months (73.71\% vs $89.12 \%), 12$ months ( $83.22 \%$ vs $92.78 \%$ ), and 24 months ( $82 \%$ vs 95.2$)$, respectively. ${ }^{47}$ A meta-analysis 
Table 3 RRP vs RARP Urinary Domain Outcomes

\begin{tabular}{|c|c|c|}
\hline \multirow{2}{*}{$\begin{array}{l}\text { Coughlin et } \mathrm{al}^{46} \\
6 \text { months }\end{array}$} & \multicolumn{2}{|c|}{ EPIC: RRP vs RARP $(95 \% \mathrm{CI})^{*}$} \\
\hline & $88.68(86.79-90.58)$ vs 88.45 (86.54-90.36) & $\mathrm{PI}<0.000 \mathrm{I}, \mathrm{P} 2<0.000 \mathrm{I}$ \\
\hline 12 months & $90.76(88.89-92.62)$ vs 91.53 (90.0I-92.98) & $\mathrm{PI}<0.000 \mathrm{I}, \mathrm{P} 2<0.000 \mathrm{I}$ \\
\hline 24 months & $91.33(89.64-93.03)$ vs $90.86(89.01-92.70)$ & $\mathrm{PI}<0.000 \mathrm{I}, \mathrm{P} 2<0.000 \mathrm{I}$ \\
\hline \multicolumn{3}{|c|}{ Pads per day (PPD) for incontinence RRP vs RARP (None, IPPD, 2PPD, 3+PPD) in \% respondents } \\
\hline 6 months & \multicolumn{2}{|c|}{$85 \%$ vs $84 \%, 13 \%$ vs $13 \%, 2 \%$ vs $2 \%, 0 \%$ vs $1 \%$} \\
\hline 12 months & \multicolumn{2}{|c|}{$91 \%$ vs $90 \%, 7 \%$ vs $10 \%, 1 \%$ vs $0 \%, 0 \%$ vs $1 \%$} \\
\hline 24 months & \multicolumn{2}{|c|}{$95 \%$ vs $91 \%, 5 \%$ vs $7 \%, 0 \%$ vs $2 \%, 0 \%$ vs $0 \%$} \\
\hline Alemozaffar et al ${ }^{43}$ & EPIC-26, Incontinence: RRP vs RARP & EPIC-26, Obstruction: RRP vs RARP \\
\hline All & $74.4 \pm 25.3$ vs $74.4 \pm 23.0, p=0.93$ & $93.9 \pm 9.6$ vs $94.5 \pm 7.5, p=0.94$ \\
\hline Low risk (D’amico) & $75.1 \pm 26.0$ vs $69.5 \pm 24.5, p=0.42$ & $93.8 \pm 9.7$ vs $95.4 \pm 7.6, p=0.72$ \\
\hline Intermediate or High Risk & $73.2 \pm 24.8$ vs $81.7 \pm 18.0, p=0.12$ & $93.5 \pm 9.9$ vs $94.4 \pm 7.4, p=0.86$ \\
\hline De Carlo et $\mathrm{al}^{47}$ & \multicolumn{2}{|c|}{ Continence Rates: use of no pads or leakage at all, RRP vs RALP } \\
\hline 6 months & \multicolumn{2}{|c|}{$73.71 \%$ vs $89.12 \%$} \\
\hline 12 months & \multicolumn{2}{|c|}{$83.22 \%$ vs $92.78 \%$} \\
\hline 24 months & \multicolumn{2}{|c|}{$82 \%$ vs $95.2 \%$} \\
\hline
\end{tabular}

Note: *Results are equivalent when both p-values significant.

by Ficarra et al also report that RARP patients may recover urinary continence faster than RRP at 12 months (OR:1.53, $\mathrm{p}=0.03$ ), but suggests that patient related factors may also play a large role in achieving early continence. ${ }^{48}$ Additionally, there are studies showing less incidence of bladder neck contracture after RARP compared to RRP, $0-3 \%$ vs $5-32 \%$, respectively. ${ }^{49,50}$ Alemozaffar et al used the EPIC instrument to compare RRP vs RARP, failing to find any difference in the urinary domain scores $(74.4 \pm 25.3$ vs $74.4 \pm 23.0)$. ${ }^{43}$ Coughlin et al compared urinary function scores in RRP vs RARP using the urinary domain of the EPIC instrument, reporting no difference at 6 months (88.68 vs 88.45), 12 months (90.76 vs $91.53)$, or 24 months (91.33 vs 90.86), respectively. ${ }^{46}$ Therefore, while several earlier studies report RARP may be superior to RRP in terms of urinary continence rates, both studies using PROM, including the only known randomized trial, failed to find any difference in urinary domain scores.

\section{Sexual Symptoms}

The comparison of sexual function suffers from similar challenges experienced when assessing urinary function in regard to study heterogeneity and validated metrics. For example, in one meta-analysis by De Carlo et al, postoperative erectile function was analyzed in 44 studies. Of these, only 8 provided accurate erectile function data, and only two used a validated PROM. ${ }^{47}$ Nevertheless, when defining potency as "erection sufficient for intercourse", De Carlo et al indicated lower rates of potency in RRP compared to RARP at 6 (22.34\% vs 32.53\%), 12 (55.85\% vs 60.93\%), and 24 months $(54.53 \%$ vs $61 \%){ }^{47}$ Another meta-analysis by Ficarra et al report a similar trend, that RARP may have better potency rates at 12 months than RRP (OR: 2.84, 95\% CI 1.46-5.43, $\mathrm{p}=0.002$ ). These results were further supported by one study using PROM. When comparing RARP to RRP, O'Neil et al report superior sexual function in RARP at 6 and 12 months. However, Alemozaffar et al used the EPIC instrument to compare RRP vs RARP, failing to find any difference in the sexual domain scores overall ( $36.3 \pm 29.7$ vs $36.8 \pm 29.5)$, or when stratified between low, intermediate, and high-risk disease. ${ }^{43}$ Furthermore, in the only randomized study with PROM as primary endpoints, Coughlin et al found no difference in sexual function domain scores when comparing RRP to RARP using two instruments at 6, 12 and 24 months (EPIC 37.40 vs 38.63, 42.28 
Table 4 RRP vs RARP Sexual Domain Outcomes

\begin{tabular}{|c|c|c|}
\hline \multirow{2}{*}{$\begin{array}{l}\text { Coughlin et } \text { al }^{46} \\
6 \text { months }\end{array}$} & \multicolumn{2}{|c|}{ EPIC: RRP vs RARP $(95 \% \mathrm{CI})^{*}$} \\
\hline & $37.40(33.60-41.19)$ vs $38.63(34.76-42.49)$ & $\mathrm{PI}<0.000 \mathrm{I}, \mathrm{P} 2<0.000 \mathrm{I}$ \\
\hline 12 months & $42.28(38.05-46.5 \mathrm{I})$ vs $42.5 \mathrm{I}$ (38.29-46.72) & $\mathrm{PI}=0.0002, \mathrm{P} 2<0.000 \mathrm{I}$ \\
\hline 24 months & $45.70(41.17-50.23)$ vs $46.90(42.20-51.60)$ & $\mathrm{PI}=0.0003, \mathrm{P} 2=0.0004$ \\
\hline \multicolumn{3}{|l|}{ IIEF: RRP vs RARP $(95 \% \mathrm{Cl})^{*}$} \\
\hline 6 months & $29.75(26.66-32.84)$ vs $29.78(26.4 I-33.16)$ & $\mathrm{PI}=0.0055, \mathrm{P} 2<0.000 \mathrm{I}$ \\
\hline 12 months & $33.10(29.59-36.61)$ vs $33.50(29.87-37.13)$ & $\mathrm{PI}=0.0 \mathrm{I} 0 \mathrm{I}, \mathrm{P} 2<0.000 \mathrm{I}$ \\
\hline 24 months & $33.95(30.11-37.78)$ vs $33.89(29.82-37.96)$ & $\mathrm{PI}=0.0012, \mathrm{P} 2<0.000 \mathrm{I}$ \\
\hline \multicolumn{3}{|c|}{ Erections Firm enough for intercourse more than half the time: RRP vs RARP } \\
\hline 6 months & $22 \%$ & $22 \%$ \\
\hline 12 months & $30 \%$ & $35 \%$ \\
\hline 24 months & $36 \%$ & $38 \%$ \\
\hline Alemozaffar et $\mathrm{al}^{43}$ & \multicolumn{2}{|c|}{ EPIC-26: RRP vs RARP } \\
\hline All & $36.3 \pm 29.7$ vs $36.8 \pm 29.5$ & $P=0.66$ \\
\hline Low risk (D’amico) & $39.7 \pm 30.0$ vs $39.4 \pm 28.7$ & $P=0.58$ \\
\hline Intermediate or High Risk & $30.7 \pm 28.1$ vs $34.2 \pm 30.3$ & $P=0.84$ \\
\hline De Carlo et $\mathrm{al}^{47}$ & \multicolumn{2}{|c|}{ Potency Rates - Erections firm enough for intercourse: RRP vs RARP } \\
\hline 6 months & $22.34 \%$ & $32.53 \%$ \\
\hline 12 months & $55.85 \%$ & $60.93 \%$ \\
\hline 24 months & $54.53 \%$ & $61.0 \%$ \\
\hline
\end{tabular}

Note: *Results are equivalent when both p-values significant.

vs $42.51,45.70$ vs 46.90 ; IIEF 29.75 vs $29.78,33.10$ vs 33.50, 33.95 vs 33.89). ${ }^{46}$ Therefore, while several earlier studies report RARP may be superior to RRP in terms of potency rates including one using PROM, two stronger studies using PROM, including the only known randomized trial, failed to find any difference in sexual domain scores. Sexual domain outcomes are summarized in Table 4.

\section{Bowel Symptoms}

Most meta-analyses reporting on the functional outcomes only in prostate surgery cohorts have not focused much attention on bowel domains. In one meta-analysis that does examine the impact of RARP on bowel domains, Alemozaffar et al used the EPIC instrument to compare RRP vs RARP, they did not notice any difference in the bowel domain scores and both remained very high overall $(96.3 \pm 7.8$ vs $96.3 \pm 9.2) .{ }^{43}$ Similarly, Coughlin et al also did not report any difference in EPIC bowel domain scores between RRP and RARP at 6
(94.04 vs 94.81), 12 (93.83 vs 95.08), and 24 months (94.49 vs 95.38). ${ }^{46}$ Therefore, both RRP and RARP have reported low negative consequences on bowel function.

\section{Financial and Anxiety Effects}

Another major consideration when measuring quality of life after intervention are the associated financial harms. Radical prostatectomy has demonstrated its cost effectiveness compared to active surveillance (AS), and RT. ${ }^{51}$ One common concern among critics of RARP over RRP are the inherited increased costs, which stem mostly from purchase of a robotics platform, service contracts, and maintenance. ${ }^{52}$ In general, RARP is known to be more costly than RRP or laparoscopic radical prostatectomy in the perioperative period. ${ }^{51,53-55}$ However, when accounting for the early postoperative cost, RARP may offer cost savings in providing decreased hospital stay, lower complication rates, and faster return to work. ${ }^{56,57}$ When comparing anxiety between RRP and RARP cohorts, 
Coughlin et al found no difference in HADS scores at 6 (6.13 vs 5.73), 12 (6.27 vs 6.05), and 24 months (6.08 vs 6.03$)^{46}$

Overall, the evidence is mixed when comparing PROM between RRP and RARP: studies report faster return and slightly better erectile function and urinary continence in RARP than RRP, however studies comparing PROM domain scores find no difference. A potential explanation may be that RARP does offer better rates of urinary continence and erectile function, but that these are not clinically significant. The paucity of data available to attempt to answer this question, compounded by data collection issues, short follow up, and study heterogeneity, prevent a convincing answer as to which surgical technique produces better functional outcomes. ${ }^{47,48,58,59}$ While these issues with the data available to answer this question are concerning, this problem is hardly new. ${ }^{60}$

\section{PROMs Comparing Treatment Modalities}

Perhaps the most consistent use of PROM reporting on RARP can be found when comparing different treatment modalities for localized disease; radiation, surgery, or active surveillance. ${ }^{4,61-63}$ These studies indicate that each treatment modality has a unique set of adverse side effects but also suggest that surgery may have the largest impact on sexual and urinary function out of the three aforementioned treatment modalities. ${ }^{4,61-63}$ It is worth noting that making these comparisons can be problematic as many studies lack long term follow up. In these cases, the side effects stemming from surgery are usually encountered up front, and thus maximally reported, while other modalities may be inadequately assessed due to time frame, for example patients who progress to metastatic disease while on active surveillance. ${ }^{4}$ Additionally, surgery is the most common initial treatment in more aggressive disease prior to planned multimodal treatment strategy. ${ }^{64}$ In at least one study comparing the EPIC domain scores of 2,550 men, prostatectomy was reported to have a larger decline in the urinary and sexual domain scores (77\% RARP) at 3 years, although no difference in global quality of life. ${ }^{61}$ van Stam et al compared 434 patients choosing RARP (only 5 open), external beam radiation therapy (EBRT), and brachytherapy (BT) to active surveillance reporting worse urinary continence rates for RARP, but worse urinary obstruction/irritation, bowel related symptom, and pain in either EBRT or BT cohorts. ${ }^{65}$ In another study using the EPIC and UCLA-PCI instruments, radiotherapy was reported to have a larger proportion of patients experiencing treatment regret at 15 year follow up $(8.2 \%$ vs $15 \%$ vs $16.6 \%$ - conservative, RARP, radiotherapy, respectively). ${ }^{66}$ Data comparing decision regret after RRP vs RARP is limited but suggests that there is no difference, and both appear low. ${ }^{67}$ Intuitively, treatment regret in RARP patients was associated with worse disease-specific quality of life secondary to side effects, although additional counseling may help overcome part of this. ${ }^{66,68}$

\section{Future Directions}

PROM have proven to be effective tools in quantifying subjective symptoms and will likely continue to play an increasingly important role in patient counseling and decision making. ${ }^{13,14}$ To facilitate reaching a larger audience, the validation of existing PROM is occurring in different languages and populations ${ }^{32,69-76}$ as well as incorporating patient perspectives into the design and execution of research studies. ${ }^{77}$ These advances promise to broaden our understanding of the patient experience and increase patient engagement in research endeavors. Furthermore, the validation of "bi-directional crosswalks" allows domain scores from one instrument to be converted into those of another, facilitating easier cross study comparison between common PROM ${ }^{38}$ Additionally, electronic and digital instruments are being used and developed, which will allow for the remote collection of PRO data in various forms. ${ }^{78}$

Lastly, with the release of newer robotics surgery platforms such as the da Vinci Single Port (SP) or Senhance robotic platform (TransEnterix Surgical Inc., Morrisville, NC, USA), surgeons may have additional options outside of the multi-port DaVinci platform currently dominating the market, but the potential benefits and costs will need to be explored prior to widespread implementation. ${ }^{5,6,79-82}$ These new directions promise to expand the utilization, reliability and widespread applicability of PRO as a critical tool for preoperative counseling and assessing postoperative outcomes following RARP.

\section{Conclusions}

The use of patient-reported outcome measures is playing an increasingly large role in urology by providing urologists with additional information with which to counsel patients when choosing between several treatment options with similar clinical outcomes and differing side effects. Urologists have developed and validated many condition specific PROM in an effort to provide more targeted assessments and information for patients and providers. This review reported on the tools available to urologists for measuring and reporting quality of life after RARP. We found that RARP offers many benefits compared to RRP in the perioperative period, with some evidence it may provide better functional outcomes in urinary continence 
and potency rates at two-year follow-up but found no significant difference in patient-reported outcome measure domain scores during the same time period. The literature in this specific area is scarce, and there is ample opportunity to continue to study PRO following RARP in future investigations. Ultimately, the use and reporting of PROM in urology will continue to expand, helping urologists to deliver higher quality care by better understanding patient needs and responding appropriately.

\section{Funding}

There is no funding to report.

\section{Disclosure}

No financial or non-financial competing interests to disclose.

\section{References}

1. Siegel RL, Miller KD, Jemal A. Cancer statistics, 2020. CA Cancer J Clin. 2020;70(1):7-30. doi:10.3322/caac.21590

2. Mohler JL, Antonarakis ES, Armstrong AJ, et al. Prostate cancer, version 2.2019, NCCN clinical practice guidelines in oncology. $J$ Natl Compr Canc Netw. 2019;17(5):479-505. doi:10.6004/ jncen.2019.0023

3. Sanda MG, Cadeddu JA, Kirkby E, et al. Clinically localized prostate cancer: AUA/ASTRO/SUO guideline. part I: risk stratification, shared decision making, and care options. J Urol. 2018;199 (3):683-690. doi:10.1016/j.juro.2017.11.095

4. Hamdy FC, Donovan JL, Lane JA, et al. 10-Year outcomes after monitoring, surgery, or radiotherapy for localized prostate cancer. $N$ Engl J Med. 2016;375(15):1415-1424. doi:10.1056/ NEJMoa 1606220

5. Oberlin DT, Flum AS, Lai JD, et al. The effect of minimally invasive prostatectomy on practice patterns of American urologists. Urol Oncol. 2016;34(6):255-e1. doi:10.1016/j.urolonc.2016.01.008

6. Lowrance WT, Eastham JA, Savage C, et al. Contemporary open and robotic radical prostatectomy practice patterns among urologists in the United States. J Urol. 2012;187(6):2087-2093. doi:10.1016/j. juro.2012.01.061

7. Binder J, Kramer W. Robotically-assisted laparoscopic radical prostatectomy. BJU International. 2001;87(4):408-410. doi:10.1046/j.1464-410x.2001.00115.x

8. Crew B. Worth the cost? A closer look at the da Vinci robot's impact on prostate cancer surgery. Nature Index Cancer. 2020;580(7804): S5-S7.

9. Leow JJ, Chang SL, Meyer CP, et al. Robot-assisted versus open radical prostatectomy: a contemporary analysis of an all-payer discharge database. Eur Urol. 2016;70(5):837-845. doi:10.1016/j. eururo.2016.01.044

10. International Health Conference. Constitution of the World Health Organization. Bull World Health Organ. 1946;80:983.

11. Guidance for industry use in medical product development to support labeling claims guidance for industry. Food and Drug Administration; 2009.

12. Milne A, Johnson JA, Tennant M, et al. Measuring health-related quality of life for patients with diabetic retinopathy. Agency for Healthcare Research and Quality (US); 2012.
13. Basch E. New frontiers in patient-reported outcomes: adverse event reporting, comparative effectiveness, and quality assessment. Annu Rev Med. 2014;65:307-317. doi:10.1146/annurev-med-010713-141500

14. Selby JV, Beal AC, Frank L. The Patient-Centered Outcomes Research Institute (PCORI) national priorities for research and initial research agenda. JAMA. 2012;307(15):1583-1584. doi:10.1001/ jama.2012.500

15. Cella D, Yount S, Rothrock N, et al. The Patient-Reported Outcomes Measurement Information System (PROMIS): progress of an NIH Roadmap cooperative group during its first two years. Med Care. 2007;45(5 Suppl 1):S3-S11. doi:10.1097/01.mlr.0000258615.42478.55

16. National Institutes of Health - Patient-reported outcomes measurement information system (PROMIS. Available from: https://www. healthmeasures.net/explore-measurement-systems/promis. Accessed March 212021.

17. Northwestern University. Health measures. Available from: https:// www.healthmeasures.net/index.php. Accessed March 212021.

18. Chen RC, Chang P, Vetter RJ, et al. Recommended patient-reported core set of symptoms to measure in prostate cancer treatment trials. J Natl Cancer Inst. 2014;106:7. doi:10.1093/jnci/dju132

19. Reeve BB, Mitchell SA, Dueck AC, et al. Recommended patient-reported core set of symptoms to measure in adult cancer treatment trials. J Natl Cancer Inst. 2014;106(7):dju129-dju129. doi:10.1093/jnci/dju129

20. Patient-Centered Outcomes Research Institute. Our Vision and Mission. Available from: https://www.pcori.org/about-us/our-visionmission. Accessed March 212021.

21. Talwar R, Dobbs RW, Stambakio H, et al. A longitudinal cohort study of pain intensity and interference after ureteroscopy for nephrolithiasis without postoperative opioids. Urology. 2021;147:81-86. doi:10.1016/j.urology.2020.09.042

22. Narang GL, Pannell SC, Laviana AA, et al. Patient-reported outcome measures in urology. Curr Opin Urol. 2017;27(4):366-374. doi:10.1097/MOU.0000000000000412

23. Miller DC, Sanda MG, Dunn RL, et al. Long-term outcomes among localized prostate cancer survivors: health-related quality-of-life changes after radical prostatectomy, external radiation, and brachytherapy. J Clin Oncol. 2005;23(12):2772-2780. doi:10.1200/ JCO.2005.07.116

24. Litwin MS, Hays RD, Fink A, et al. Quality-of-life outcomes in men treated for localized prostate cancer. JAMA. 1995;273(2):129-135. doi:10.1001/jama.1995.03520260051032

25. Wei JT, Dunn RL, Sandler HM, et al. Comprehensive comparison of health-related quality of life after contemporary therapies for localized prostate cancer. J Clin Oncol. 2002;20(2):557-566. doi:10.1200/JCO.2002.20.2.557

26. Madalinska JB, Essink-Bot M-L, de Koning HJ, et al. Health-related quality-of-life effects of radical prostatectomy and primary radiotherapy for screen-detected or clinically diagnosed localized prostate cancer. J Clin Oncol. 2001;19(6):1619-1628. doi:10.1200/ JCO.2001.19.6.1619

27. Talcott JA, Rieker P, Clark JA, et al. Patient-reported symptoms after primary therapy for early prostate cancer: results of a prospective cohort study. J Clin Oncol. 1998;16(1):275-283. doi:10.1200/ JCO.1998.16.1.275

28. Talcott JA, Rieker P, Propert KJ, et al. Patient-reported impotence and incontinence after nerve-sparing radical prostatectomy. $J$ Natl Cancer Inst. 1997;89(15):1117-1123. doi:10.1093/jnci/89.15.1117

29. Litwin MS, McGuigan KA. Accuracy of recall in health-related quality-of-life assessment among men treated for prostate cancer. $J \quad$ Clin Oncol. 1999;17(9):2882-2888. doi:10.1200/ JCO.1999.17.9.2882

30. Cappelleri JC, Rosen RC. The Sexual Health Inventory for Men (SHIM): a 5-year review of research and clinical experience. Int J Impot Res. 2005;17(4):307-319. doi:10.1038/sj.ijir.3901327 
31. Weinfurt KP, Lin L, Bruner DW, et al. Development and initial validation of the PROMIS ${ }^{\circledR}$ sexual function and satisfaction measures version 2.0. J Sex Med. 2015;12(9):1961-1974. doi:10.1111/ jsm. 12966

32. Rosen RC, Riley A, Wagner G, et al. The international index of erectile function (IIEF): a multidimensional scale for assessment of erectile dysfunction. Urology. 1997;49(6):822-830. doi:10.1016/ S0090-4295(97)00238-0

33. Esper P, Mo F, Chodak G, et al. Measuring quality of life in men with prostate cancer using the functional assessment of cancer therapy-prostate instrument. Urology. 1997;50(6):920-928. doi:10.1016/S0090-4295(97)00459-7

34. Wei JT, Dunn RL, Litwin MS, et al. Development and validation of the expanded prostate cancer index composite (EPIC) for comprehensive assessment of health-related quality of life in men with prostate cancer. Urology. 2000;56(6):899-905. doi:10.1016/S00904295(00)00858-X

35. Borghede G, Sullivan M. Measurement of quality of life in localized prostatic cancer patients treated with radiotherapy. Development of a prostate cancer-specific module supplementing the EORTC QLQ-C30. Qual Life Res. 1996;5(2):212-222. doi:10.1007/BF00434743

36. Ware JE, Sherbourne CD. The MOS 36-item short-form health survey (SF-36). I. Conceptual framework and item selection. Med Care. 1992;30(6):473-483. doi:10.1097/00005650-199206000-00002

37. Litwin MS, Hays RD, Fink A, et al. The UCLA Prostate Cancer Index: development, reliability, and validity of a health-related quality of life measure. Med Care. 1998;36(7):1002-1012. doi:10.1097/ 00005650-199807000-00007

38. Singh K, Tin AL, Dunn RL, et al. Development and validation of crosswalks for patient-reported sexual and urinary outcomes between commonly used instruments. Eur Urol. 2019;75(5):723-730. doi:10.1016/j.eururo.2018.12.002

39. Dobbs RW, Magnan BP, Abhyankar N, et al. Cost effectiveness and robot-assisted urologic surgery: does it make dollars and sense? Minerva Urol Nefrol. 2017;69(4):313-323. doi:10.23736/S03932249.16.02866-6

40. Novara G, Ficarra V, Rosen RC, et al. Systematic review and meta-analysis of perioperative outcomes and complications after robot-assisted radical prostatectomy. Eur Urol. 2012;62(3):431-452. doi:10.1016/j.eururo.2012.05.044

41. Yaxley JW, Coughlin GD, Chambers SK, et al. Robot-assisted laparoscopic prostatectomy versus open radical retropubic prostatectomy: early outcomes from a randomised controlled Phase 3 study. Lancet. 2016;388(10049):1057-1066. doi:10.1016/S0140-6736(16)30592-X

42. Akand M, Celik O, Avci E, et al. Open, laparoscopic and robot-assisted laparoscopic radical prostatectomy: comparative analysis of operative and pathologic outcomes for three techniques with a single surgeon's experience. Eur Rev Med Pharmacol Sci. 2015;19(4):525-531.

43. Alemozaffar M, Sanda M, Yecies D, et al. Benchmarks for operative outcomes of robotic and open radical prostatectomy: results from the health professionals follow-up study. Eur Urol. 2015;67(3):432-438. doi:10.1016/j.eururo.2014.01.039

44. Murphy D, Challacombe B, Khan MS, et al. Robotic technology in urology. Postgrad Med J. 2006;82(973):743-747. doi:10.1136/ pgmj.2006.048140

45. O'Neil B, Koyama T, Alvarez J, et al. The comparative harms of open and robotic prostatectomy in population based samples. $J$ Urol. 2016;195(2):321-329. doi:10.1016/j.juro.2015.08.092

46. Coughlin GD, Yaxley JW, Chambers SK, et al. Robot-assisted laparoscopic prostatectomy versus open radical retropubic prostatectomy: 24-month outcomes from a randomised controlled study. Lancet Oncol. 2018;19(8):1051-1060. doi:10.1016/S1470-2045(18)30357-7

47. De Carlo F, Celestino F, Verri C, et al. Retropubic, laparoscopic, and robot-assisted radical prostatectomy: surgical, oncological, and functional outcomes: a systematic review. Urol Int. 2014;93(4):373-383. doi: $10.1159 / 000366008$
48. Ficarra V, Novara G, Rosen RC, et al. Systematic review and meta-analysis of studies reporting urinary continence recovery after robot-assisted radical prostatectomy. Eur Urol. 2012;62(3):405-417. doi:10.1016/j.eururo.2012.05.045

49. Breyer BN, Davis CB, Cowan JE, et al. Incidence of bladder neck contracture after robot-assisted laparoscopic and open radical prostatectomy. BJU International. 2010;106(11):1734-1738. doi:10.1111/j.1464-410X.2010.09333.x

50. Msezane LP, Reynolds WS, Gofrit ON, et al. Bladder neck contracture after robot-assisted laparoscopic radical prostatectomy: evaluation of incidence and risk factors and impact on urinary function. $J$ Endourol. 2008;22(1):97-104. doi:10.1089/end.2006.0460

51. Sharma V, Wymer KM, Borah BJ, et al. Cost-effectiveness of active surveillance, radical prostatectomy and external beam radiotherapy for localized prostate cancer: an analysis of the protect trial. $J$ Urol. 2019;202(5):964-972. doi:10.1097/JU.0000000000000345

52. Tomaszewski JJ, Matchett JC, Davies BJ, et al. Comparative hospital cost-analysis of open and robotic-assisted radical prostatectomy. Urology. 2012;80(1):126-129. doi:10.1016/j. urology.2012.03.020

53. Bolenz C, Gupta A, Hotze T, et al. Cost comparison of robotic, laparoscopic, and open radical prostatectomy for prostate cancer. Eur Urol. 2010;57(3):453-458. doi:10.1016/j.eururo.2009.11. 008

54. Mukherjee K, Kamal KM. Variation in prostate surgery costs and outcomes in the USA: robot-assisted versus open radical prostatectomy. J Comp Eff Res. 2019;8(3):143-155. doi:10.2217/cer-2018-0109

55. Forsmark A, Gehrman J, Angenete E, et al. Health economic analysis of open and robot-assisted laparoscopic surgery for prostate cancer within the prospective multicentre LAPPRO trial. Eur Urol. 2018;74 (6):816-824. doi:10.1016/j.eururo.2018.07.038

56. Close A, Robertson C, Rushton S, et al. Comparative cost-effectiveness of robot-assisted and standard laparoscopic prostatectomy as alternatives to open radical prostatectomy for treatment of men with localised prostate cancer: a health technology assessment from the perspective of the UK National Health Service. Eur Urol. 2013;64(3):361-369. doi:10.1016/j.eururo.2013.02.040

57. Bijlani A, Hebert AE, Davitian M, et al. A multidimensional analysis of prostate surgery costs in the United States: robotic-assisted versus retropubic radical prostatectomy. Value Health. 2016;19(4):391-403. doi:10.1016/j.jval.2015.12.019

58. Moran PS, O'Neill M, Teljeur C, et al. Robot-assisted radical prostatectomy compared with open and laparoscopic approaches: a systematic review and meta-analysis. Int $J$ Urol. 2013;20 (3):312-321. doi:10.1111/iju.12070

59. Ficarra V, Novara G, Ahlering TE, et al. Systematic review and meta-analysis of studies reporting potency rates after robot-assisted radical prostatectomy. Eur Urol. 2012;62(3):418-430. doi:10.1016/j. eururo.2012.05.046

60. Kang DC, Hardee MJ, Fesperman SF, et al. Low quality of evidence for robot-assisted laparoscopic prostatectomy: results of a systematic review of the published literature. Eur Urol. 2010;57(6):930-937. doi:10.1016/j.eururo.2010.01.034

61. Barocas DA, Alvarez J, Resnick MJ, et al. Association between radiation therapy, surgery, or observation for localized prostate cancer and patient-reported outcomes after 3 years. JAMA. 2017;317 (11):1126-1140. doi:10.1001/jama.2017.1704

62. Punnen S, Cowan JE, Chan JM, et al. Long-term health-related quality of life after primary treatment for localized prostate cancer: results from the CaPSURE registry. Eur Urol. 2015;68(4):600-608. doi:10.1016/j.eururo.2014.08.074

63. Chen RC, Basak R, Meyer AM, et al. Association between choice of radical prostatectomy, external beam radiotherapy, brachytherapy, or active surveillance and patient-reported quality of life among men with localized prostate cancer. JAMA. 2017;317(11):1141-1150. doi:10.1001/jama.2017.1652 
64. Wu AK, Cooperberg MR, Sadetsky N, et al. Health related quality of life in patients treated with multimodal therapy for prostate cancer. J Urol. 2008;180(6):2415-2422. doi:10.1016/j.juro.2008.08.015

65. van Stam MA, Aaronson NK, Bosch JLHR, et al. Patient-reported outcomes following treatment of localised prostate cancer and their association with regret about treatment choices. Eur Urol Oncol. 2020;3(1):21-31. doi:10.1016/j.euo.2018.12.004

66. Hoffman RM, Lo M, Clark JA, et al. Treatment decision regret among long-term survivors of localized prostate cancer: results from the prostate cancer outcomes study. J Clin Oncol. 2017;35 (20):2306-2314. doi:10.1200/JCO.2016.70.6317

67. Baunacke M, Schmidt ML, Groeben C, et al. Decision regret after radical prostatectomy does not depend on surgical approach: 6-year followup of a large german cohort undergoing routine care. J Urol. 2020;203(3):554-561. doi:10.1097/JU.0000000000000541

68. Lindsay J, Uribe S, Moschonas D, et al. Patient satisfaction and regret after robot-assisted radical prostatectomy: a decision regret analysis. Urology. 2021;149:122-128. doi:10.1016/j.urology.2020.12.015

69. Lam WWT, Tse MA, Ng CNL, et al. Psychometric assessment of the Chinese version of the abbreviated expanded prostate cancer index composite (EPIC-26) and the clinical practice version (EPIC-CP) in Chinese men with prostate cancer. J Pain Symptom Manage. 2017;53 (6):1085-1090. doi:10.1016/j.jpainsymman.2017.02.010

70. Marzorati C, Monzani D, Mazzocco K, et al. Validation of the Italian version of the abbreviated expanded prostate Cancer index composite (EPIC-26) in men with prostate Cancer. Health Qual Life Outcomes. 2019;17(1):147. doi:10.1186/s12955-019-1214-x

71. Axcrona K, Nilsson R, Brennhovd B, et al. Psychometric properties of the expanded prostate cancer index composite - 26 instrument in a cohort of radical prostatectomy patients: theoretical and practical examinations. BMC Urol. 2017;17(1):111. doi:10.1186/s12894-017-0302-7

72. Takegami M, Suzukamo Y, Sanda MG, et al. [The Japanese translation and cultural adaptation of Expanded Prostate Cancer Index Composite (EPIC)]. Nihon Hinyokika Gakkai Zasshi. 2005;96 (7):657-669. [Japanese]. doi:10.5980/jpnjurol1989.96.657

73. Alves E, Medina R, Andreoni C. Validation of the Brazilian version of the Expanded Prostate Cancer Index Composite (EPIC) for patients submitted to radical prostatectomy. Int Braz J Urol. 2013;39(3):344-352. doi:10.1590/S1677-5538.IBJU.2013.03.07
74. Anota A, Mariet AS, Maingon P, et al. Cross-cultural adaptation and validation of the French version of the Expanded Prostate cancer Index Composite questionnaire for health-related quality of life in prostate cancer patients. Health Qual Life Outcomes. 2016;14(1):168. doi:10.1186/s12955-016-0571-y

75. Umbehr MH, Bachmann LM, Poyet C, et al. The German version of the Expanded Prostate Cancer Index Composite (EPIC): translation, validation and minimal important difference estimation. Health Qual Life Outcomes. 2018;16(1):36. doi:10.1186/s12955-018-0859-1

76. Izard JP. The emerging role of patient-reported outcomes in urology. Can Urol Assoc J. 2017;11(12):411. doi:10.5489/cuaj.5007

77. Lee DJ, Avulova S, Conwill R, et al. Patient engagement in the design and execution of urologic oncology research. Urol Oncol. 2017;35(9):552-558. doi:10.1016/j.urolonc.2017.07.002

78. Tran C, Dicker A, Leiby B, et al. Utilizing digital health to collect electronic patient-reported outcomes in prostate cancer: single-arm pilot trial. J Med Internet Res. 2020;22(3):e12689. doi:10.2196/ 12689

79. Dobbs RW, Halgrimson WR, Madueke I, et al. Single-port robotassisted laparoscopic radical prostatectomy: initial experience and technique with the da Vinci $^{\circledR}$ SP platform. BJU Int. 2019;124 (6):1022-1027. doi:10.1111/bju.14864

80. Lai A, Dobbs RW, Talamini S, et al. Single port robotic radical prostatectomy: a systematic review. Transl Androl Urol. 2020;9 (2):898-905. doi:10.21037/tau.2019.11.05

81. Dobbs RW, Halgrimson WR, Talamini S, et al. Single-port robotic surgery: the next generation of minimally invasive urology. World J Urol. 2020;38(4):897-905. doi:10.1007/s00345-019-02898-1

82. Samalavicius NE, Janusonis V, Siaulys R, et al. Robotic surgery using Senhance $((\mathrm{R}))$ robotic platform: single center experience with first 100 cases. J Robot Surg. 2020;14(2):371-376. doi:10.1007/ s11701-019-01000-6

\section{Publish your work in this journal}

Patient Preference and Adherence is an international, peer-reviewed, open access journal that focusing on the growing importance of patient preference and adherence throughout the therapeutic continuum. Patient satisfaction, acceptability, quality of life, compliance, persistence and their role in developing new therapeutic modalities and compounds to optimize clinical outcomes for existing disease states are major areas of interest for the journal. This journal has been accepted for indexing on PubMed Central. The manuscript management system is completely online and includes a very quick and fair peer-review system, which is all easy to use. Visit http:// www.dovepress.com/testimonials.php to read real quotes from published authors. 